\title{
Estado de conservação e domínios fitogeográficos das espécies utilizadas pela comunidade quilombola Santa Cruz, Brejo Grande/SE
}

\author{
Ray Santos Andrade ${ }^{(\mathrm{a})}$, Neise Mare de Souza Alves ${ }^{(\mathrm{b})}$, Marta Cristina Vieira Farias ${ }^{(\mathrm{c})}$, Bruna \\ Leidiane Pereira Santana ${ }^{(\mathrm{d})}$
}

(a) Departamento de Biologia, Universidade Federal de Sergipe, raybiotanica@gmail.com

(b) Departamento de Geografia, Universidade Federal de Sergipe, neisemare@gmail.com

(c) Departamento de Biologia, Universidade Federal de Sergipe, marta.ase@ gmail.com

(d) Departamento de Geografia, Universidade Federal de Sergipe, bruna.leydiane@gmail.com

\section{EIXO: BIOGEOGRAFIA, MANEJO DE ÁREAS NATURAIS E PROTEGIDAS: CONSERVAÇÃO DA BIODIVERSIDADE}

\begin{abstract}
Resumo:
Pesquisas sobre a biodiversidade brasileira e distribuição geográfica das espécies vegetais se encontram em estágio exploratório. Diante disso, o presente trabalho tem por objetivo analisar o estado de conservação das espécies utilizadas pela comunidade quilombola Santa Cruz, Brejo Grande/SE, identificando os domínios fitogeográficos brasileiros onde as mesmas se distribuem. Os estudos se baseiam nos pressupostos geossistêmicos, que se harmoniza com a análise integrada da paisagem. O material botânico coletado foi herborizado e levado ao Herbário ASE para identificação. As espécies foram classificadas quanto ao grau de ameaça de extinção, enquanto a distribuição fitogeográfica se deu mediante consultas ao banco de dados Flora do Brasil. Os resultados permitiram constatar que a maioria das espécies apresenta ampla distribuição, à exceção das seguintes: joazeiro (Ziziphus joazeiro Mart.) e gameleiro (Ficus cyclophylla (Miq.) Miq.). As análises também indicaram que a espécie $F$. cyclophylla se encontra ameaçada, sendo classificada em situação de perigo pelo IUCN.
\end{abstract}

Palavras-chave: Brejo Grande; Comunidades tradicionais; Conservação; Domínios fitogeográficos.

\section{Introdução}

Os ecossistemas pertencentes ao território brasileiro dispõem de expressiva diversidade biológica. Mas, nos últimos anos, essa diversidade vem sendo destruída. (NASCIMENTO; LONGHI; BRENA, 2001). A perda de espécies tem como principal causa à devastação ou superexploração dos habitats, decorrentes de desmatamentos, do aumento de aglomerados urbanos, de mudanças climáticas, da introdução de espécies exóticas invasoras e da contaminação do meio ambiente (DRUMMOND, et al., 2009).

Estes impactos trazem consequências negativas para a fauna e a flora, afetando cada vez mais a sua capacidade de fornecer serviços ecossistêmicos para o bem-estar humano, ora pela redução do recurso devido à exploração exagerada ora pela incapacidade de autorregulação dos sistemas naturais (KETTUNEN; TEN BRINK, 2006). 
Estima-se que a flora brasileira é considerada a mais rica do mundo, com aproximadamente 56.000 espécies (GIULIETTI, et al., 2005). Essa riqueza se deve a diversos componentes ambientais, dos quais se destacam o solo, o clima, o relevo e os recursos hídricos que interagem entre si e simultaneamente, proporcionando o desenvolvimento de uma cobertura vegetal singular, que se distribui nos diversos biomas do Brasil (DRUMMOND, et al., 2009).

A repartição desses vegetais na superfície terrestre e a análise dos fatores bióticos e abióticos que caracterizam os sistemas naturais constituem o objeto de estudo da Biogeografia (PASSOS, 2003). Essa ciência se dedica a estudar "[...] a distribuição geográfica dos seres vivos no espaço através do tempo, com o objetivo de entender os padrões de organização espacial dos organismos e os processos que resultaram em tais padrões" (GILLUNG, 2011, p. 1).

Estudos científicos sobre a biodiversidade brasileira e a distribuição geográfica das espécies vegetais ainda se encontram em estágio exploratório (GIULIETTI, et al., 2005). Portanto, ainda há uma necessidade de inventários, pois o acelerado processo de destruição da flora tem levado a perdas inestimáveis de espécies, muitas ainda desconhecidas no meio científico e que podem trazer benefícios para as comunidades tradicionais, que dependem diretamente dos recursos vegetais fornecidos pela natureza.

À vista disso, o presente trabalho tem por objetivo analisar o estado de conservação de espécies utilizadas pela comunidade quilombola Santa Cruz, Brejo Grande/SE, identificando os domínios fitogeográficos brasileiros onde as mesmas se distribuem.

\section{Caracterização da área de estudo}

Brejo Grande é um município situado no Baixo São Francisco Sergipano, com extensão territorial de 148 $\mathrm{km}^{2}$ (IBGE, 2017). Limita-se ao norte com o estado de Alagoas, ao sul com Pacatuba, a leste com o oceano Atlântico e a oeste com o município de Ilha das Flores. O povoado Brejão dos Negros localiza-se ao sul da sede municipal. Seu acesso a partir de Aracaju ocorre através da rodovia SE-100, seguindo a SE204 (Figura 1).

Regionalmente, o clima se caracteriza como sendo do tipo megatérmico úmido/subúmido com temperatura média anual elevada e precipitações concentradas no outono-inverno, com cerca de $1300 \mathrm{~mm}$ anuais. Os meses com menores índices pluviométricos correspondem às estações primavera-verão (ALVES, 2010).

O conjunto florístico de Brejo Grande é constituído por Formações Pioneiras de Áreas de Influência Marinha caracterizada pelas espécies da Restinga, Formações Pioneiras de Influência Fluvial 
correspondentes aos Campos de Várzeas e, Formações Pioneiras de Influência Fluviomarinha, representadas pela vegetação de Mangue e ecossistema Manguezal (BRASIL, 1983).

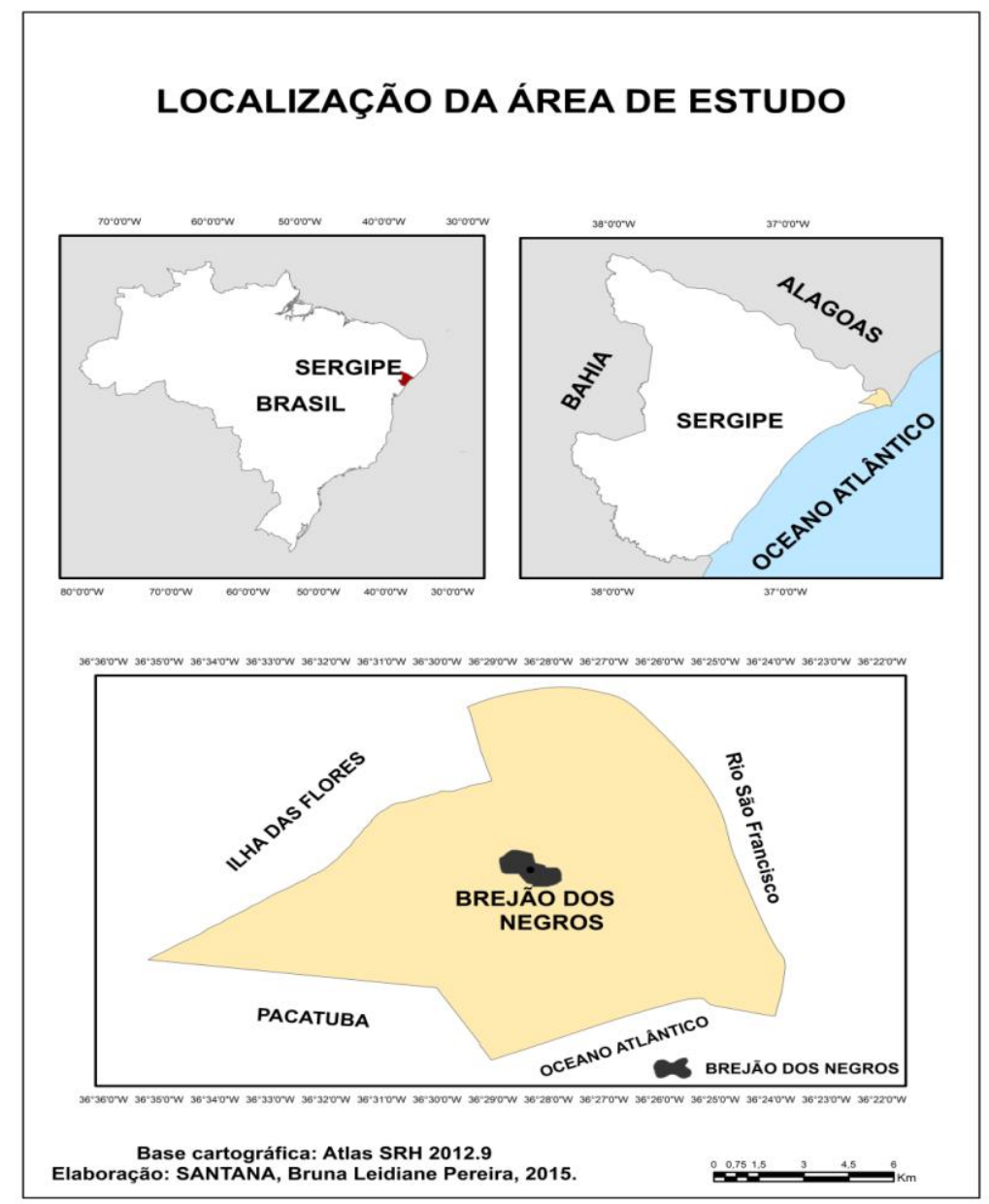

Figura 1 - Mapa de localização de Brejão dos Negros, Brejo Grande-SE.

Fonte: Santana (2017)

De acordo com ALVES (2010), as espécies herbáceas, arbustivas e arbóreas da Restinga distribuem-se espacialmente sobre os Neossolos Quartzarênicos (Figura 2). Os tipos de Mangue, de acordo com a sua adaptabilidade, podem colonizar um dos seguintes setores da planície Fluviomarinha: o substrato lamoso com matéria orgânica (zona de Intermaré, inundada diariamente pelas marés) ou a cobertura arenosa e hipersalina (zona de Supramaré, inundada eventualmente nas marés de sizígia). Localmente, foram identificadas espécies arbóreas do Mangue bravo ou vermelho (Rhizophora mangle L.), representado na Figura 3, e Mangue manso ou branco (Laguncularia racemosa (L.) C. F. Gaertn.). 


$\begin{aligned} & \text { XVII Simpósio Brasileiro } \\ & \text { de Geografia Fisica Aplicada }\end{aligned}$
$\begin{aligned} & \text { I Congresso Nacional } \\ & \text { de Geografia Física }\end{aligned}$

Os Campos de Várzeas associam-se aos Gleissolos Háplicos e Neossolos Flúvicos (ALVES , 2010). Essa formação vegetal é típica dos terrenos alagadiços, que caracterizam as planícies de inundação dos canais fluviais e depressões situadas nas proximidades das áreas de Mangue e Restinga (Figura 4).

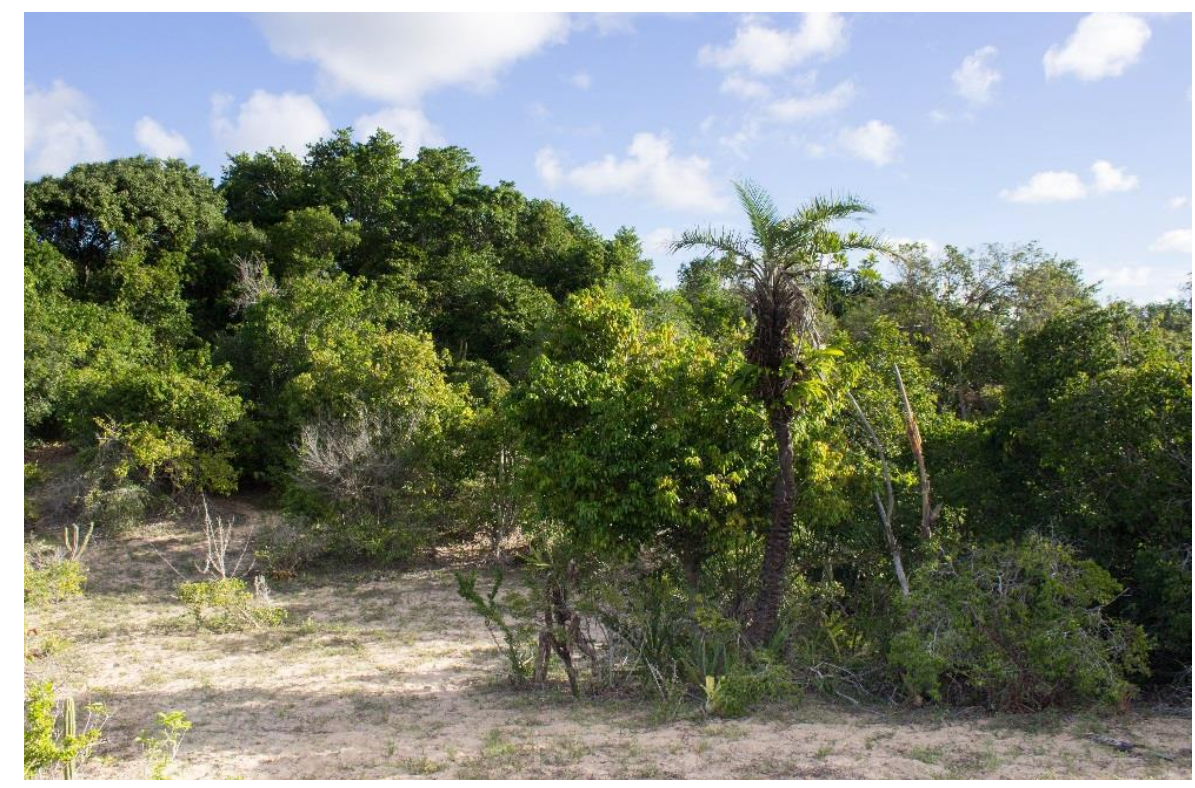

Figura 2 - Vegetação de Restinga, Brejo Grande-SE.

Fonte: Santana (2016).

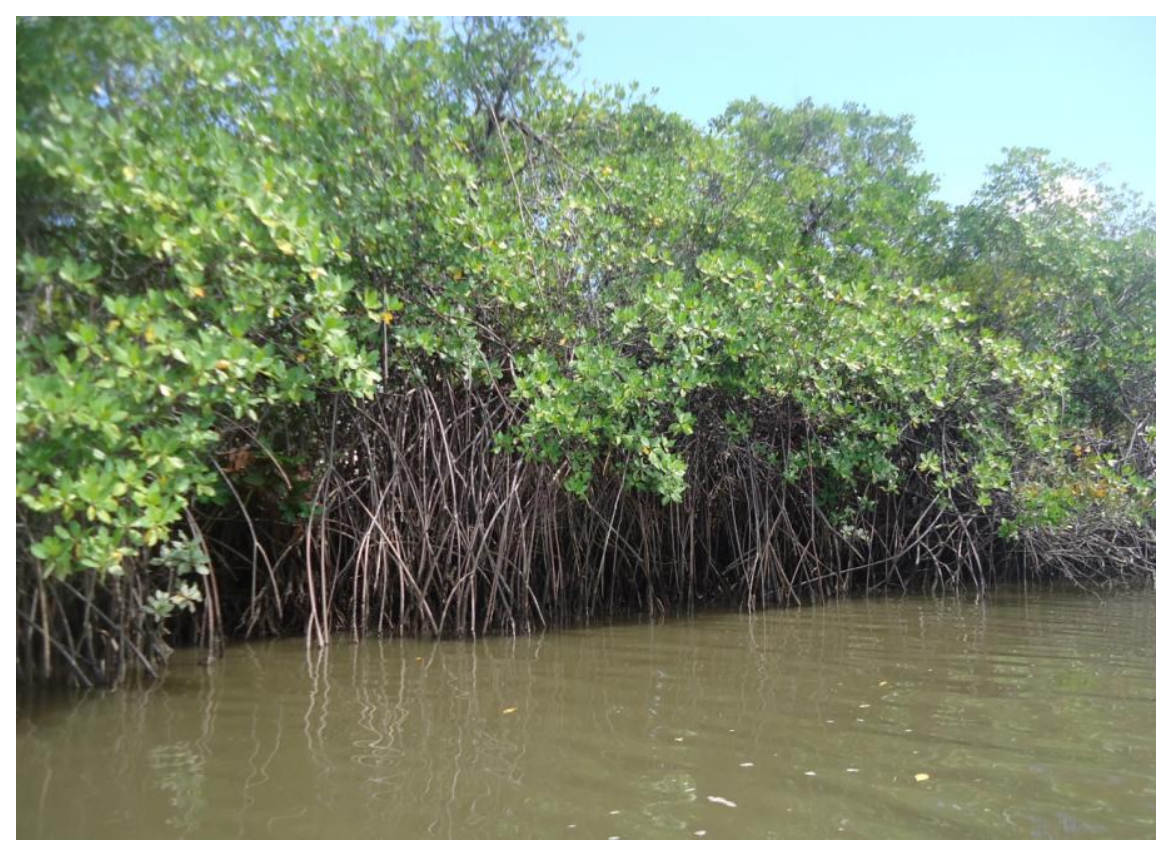

Figura 3 - Rhizophora mangle L. na margem esquerda do rio Parapuca, Brejo Grande-SE.

Fonte: Santana (2015). 


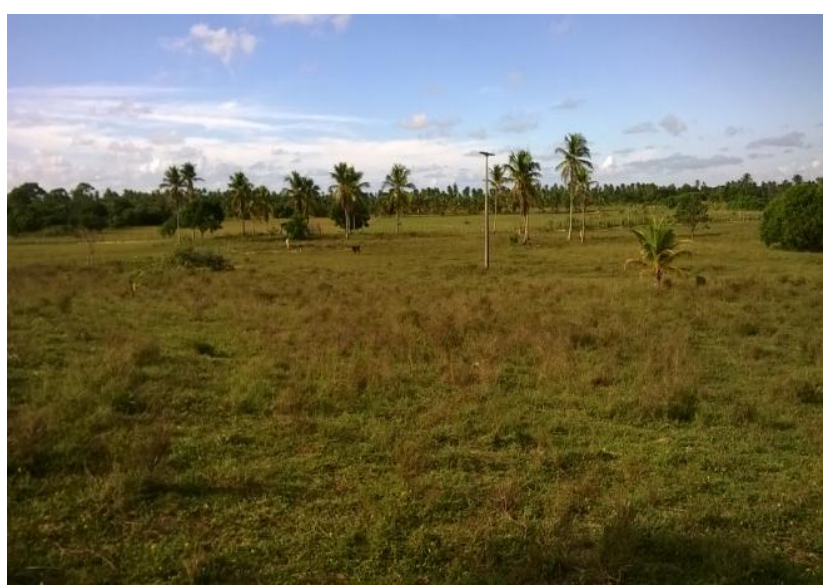

Figura 4 - Área de Campos de Várzea ocupada por pastagem e coqueiros esparsos, Brejo Grande-SE.

Fonte: Santana (2015).

No quadro geomorfológico de Brejo Grande é representado pela Planície Costeiro-Deltaica do Rio São Francisco. A evolução desta unidade está associada aos eventos climáticos do Quaternário, que proporcionaram flutuações no nível marinho. Assim, as feições morfológicas - Terraços marinhos holocênicos atuais, Dunas costeiras inativas, Planície fluviolagunar e Planície de maré inferior - compõem a unidade geomorfológica referida (ALVES, 2010).

\section{Metodologia}

O desenvolvimento do presente estudo se baseia nos princípios da abordagem sistêmica representada pelo modelo teórico-metodológico Geossistêmico de Bertrand (1972), que entende a paisagem de forma integrada e dinâmica, tendo como base a relação entre os componentes naturais - solo, clima, vegetação, geomorfologia, geologia, hidrografia e a ação antrópica.

Para a realização do levantamento da flora fanerogâmica do conjunto florístico foram realizados trabalhos de campo na vegetação de Restinga, para coleta de material fértil (com flor e/ou fruto), através de caminhadas sempre acompanhadas pelos moradores da comunidade quilombola Santa Cruz, que forneciam os nomes populares das espécies e seus respectivos usos.

O material coletado foi herborizado, segundo técnicas usuais (MORI et al., 1985) e levado ao Herbário ASE para identificação, através de consultas à literatura científica e comparação com as exsicatas do seu acervo, sendo utilizado o sistema de classificação do Angiosperm Philogeny Group IV (APG, 2016) e nomenclatura atualizada. 
Para classificação das espécies quanto ao grau de ameaça na região, foram realizadas consultas à três bases de dados: plataforma da International Union for Conservation of Nature (IUCN, 2017), lista oficial da Flora Brasileira Ameaçada de Extinção do Ministério do Meio Ambiente e lista da Flora Brasileira Ameaçada de extinção, segundo Avaliação no Workshop da Fundação Biodiversitas. De modo semelhante, a distribuição destas espécies em seus respectivos domínios fitogeográficos foi obtida mediante consulta à lista de espécies da Flora do Brasil (2017).

\section{Resultados e Discussão}

A mata de Restinga tem importância para a comunidade quilombola Santa Cruz, que depende diretamente de seus recursos florísticos. Os membros que ali se instalaram reconhecem o uso de 29 espécies vegetais, as quais são empregadas na alimentação, no tratamento de enfermidades, na construção de moradia e até mesmo na confecção de utensílios. Dentre as espécies que compõem a flora na área em que residem as famílias quilombolas, há uma que é originária da África, o dendê (Elaeis guineensis Jacq.).

Ressalta-se que na tabela I consta o nome científico das espécies ocorrentes na área de estudo, seguido do nome popular e dos respectivos domínios de distribuição fitogeográfica no Brasil. E, embora a espécie supracitada não se inclua entre as plantas nativas do país, ela foi mantida em virtude de ser referência de uso e consumo na comunidade Santa Cruz.

Tabela I - Lista das famílias e espécies utilizadas pela comunidade de Santa Cruz, Brejo Grande-SE, e respectivos nomes populares e domínios fitogeográficos de distribuição no Brasil, representados nas siglas: Am - Amazônia,

$\mathrm{Ca}$ - Caatinga, Ce - Cerrado, Ma - Mata Attântica, Pa - Pampa, Pan - Pantanal

\begin{tabular}{|l|l|l|}
\hline Família/ Espécie & $\begin{array}{l}\text { Nome } \\
\text { popular }\end{array}$ & $\begin{array}{l}\text { Distribuição no Domínio } \\
\text { fitogeográfico brasileiro }\end{array}$ \\
\hline ANACARDIACEAE & & \\
\hline Schinus terebinthifolia Raddi. & Aroeira & $\mathrm{Ce}, \mathrm{Ma}, \mathrm{Pa}$ \\
\hline Anacardium occidentale L. & Cajueiro & $\mathrm{Am}, \mathrm{Ca}, \mathrm{Ce}, \mathrm{Ma}, \mathrm{Pa}, \mathrm{Pan}$ \\
\hline Tapirira guianensis Aubl. & Pau-pombo & $\mathrm{Am}, \mathrm{Ca}, \mathrm{Ce}, \mathrm{Ma}, \mathrm{Pa}, \mathrm{Pan}$ \\
\hline ANNONACEAE & & \\
\hline Xylopia laevigata (Mart.) R. E. Fr. & Meiú & $\mathrm{Ca}, \mathrm{Ce}, \mathrm{Ma}$ \\
\hline APOCYNACEAE & & \\
\hline Mandevilla hirsuta (A. Rich.) K. Schum. & Camaleão & $\mathrm{Am}, \mathrm{Ca}, \mathrm{Ce}, \mathrm{Ma}$ \\
\hline ARACEAE & & \\
\hline Philodendron acutatum Schott & Imbé & $\mathrm{Am}, \mathrm{Ca}, \mathrm{Ce}, \mathrm{Ma}$ \\
\hline ARECACEAE & & \\
\hline Syagrus coronata (Mart.) Becc. & Aricuri & $\mathrm{Ca}, \mathrm{Ce}$ \\
\hline Elaeis guineensis Jacq. & Dendê & $\mathrm{Ma}$ \\
\hline
\end{tabular}


XVII Simpósio Brasileiro de Geografia Física Aplicada

I Congresso Nacional de Geografia Física
OS DESAFIOS DA GEOGRAFIA FÍSICA NA FRONTEIRA DO CONHECIMENTO

Instituto de Geociências - Unicamp

Campinas - SP

28 de Junho à 02 de Julho de 2017

\begin{tabular}{|c|c|c|}
\hline BIGNONIACEAE & & \\
\hline Lundia corymbifera (Vahl) Sandwith & Cipó & $\mathrm{Am}, \mathrm{Ma}$ \\
\hline \multicolumn{3}{|l|}{ BROMELIACEAE } \\
\hline Hohenbergia catingae Ule & Gravatá & $\mathrm{Ca}, \mathrm{Ce}, \mathrm{Ma}$ \\
\hline \multicolumn{3}{|l|}{ BURSERACEAE } \\
\hline Protium heptaphyllum (Aubl.) Marchand & Amescla & $\mathrm{Am}, \mathrm{Ca}, \mathrm{Ce}, \mathrm{Ma}$ \\
\hline \multicolumn{3}{|l|}{ CACTACEAE } \\
\hline Cereus fernambucensis Lem. & Cardeiro & Am, Ma \\
\hline \multicolumn{3}{|l|}{ FABACEAE } \\
\hline Andira fraxinifolia Benth & Angelim & $\mathrm{Ca}, \mathrm{Ce}, \mathrm{Ma}$ \\
\hline $\begin{array}{l}\text { Chamaecrista hispidula (Vahl) H. S. Irwin \& } \\
\text { Barneby }\end{array}$ & Carobinha & $\mathrm{Am}, \mathrm{Ca}, \mathrm{Ce}, \mathrm{Ma}$ \\
\hline Senna occidentalis (L.) Link & Fedegoso & $\mathrm{Am}, \mathrm{Ca}, \mathrm{Ce}, \mathrm{Ma}, \mathrm{Pan}$ \\
\hline Inga capitata Desv. & Ingá & $\mathrm{Am}, \mathrm{Ma}$ \\
\hline Hymenaea courbaril $\mathrm{L}$. & Jatobá & $\mathrm{Am}, \mathrm{Ca}, \mathrm{Ce}, \mathrm{Ma}, \mathrm{Pan}$ \\
\hline Centrosema brasilianum (L.) Benth. & Piriquito & $\mathrm{Am}, \mathrm{Ca}, \mathrm{Ce}, \mathrm{Ma}, \mathrm{Pan}$ \\
\hline \multicolumn{3}{|l|}{ MELASTOMATACEAE } \\
\hline Mouriri guianensis Aubl & Cruirí & $\mathrm{Am}, \mathrm{Ca}, \mathrm{Ce}, \mathrm{Ma}$ \\
\hline \multicolumn{3}{|l|}{ MORACEAE } \\
\hline Ficus cyclophylla (Miq.) Miq. & Gameleiro & $\mathrm{Ma}$ \\
\hline \multicolumn{3}{|l|}{ MYRTACEAE } \\
\hline Myrciaria floribunda (H.West ex Willd.) O. Berg & Cambuí & $\mathrm{Am}, \mathrm{Ca}, \mathrm{Ce}, \mathrm{Ma}$ \\
\hline Campomanesia ilhoensis Mattos & Gabiroba & $\mathrm{Ca}, \mathrm{Ma}$ \\
\hline Eugenia pyriformis Cambess. & Ubaia & $\mathrm{Ce}, \mathrm{Ma}$ \\
\hline \multicolumn{3}{|l|}{ PASSIFLORACEAE } \\
\hline Passiflora silvestris Vell. & $\begin{array}{l}\text { Maracujá-do- } \\
\text { mato }\end{array}$ & $\mathrm{Ce}, \mathrm{Ma}$ \\
\hline \multicolumn{3}{|l|}{ PERACEAE } \\
\hline Pera glabrata (Schott) Poepp. ex Baill. & Sete cascos & $\mathrm{Am}, \mathrm{Ca}, \mathrm{Ce}, \mathrm{Ma}$ \\
\hline \multicolumn{3}{|l|}{ RHAMNACEAE } \\
\hline Ziziphus joazeiro Mart. & Juá & $\mathrm{Ca}$ \\
\hline \multicolumn{3}{|l|}{ RUBIACEAE } \\
\hline Tocoyena formosa (Cham. \& Schltdl.) K. Schum. & Genipapinho & $\mathrm{Am}, \mathrm{Ca}, \mathrm{Ce}, \mathrm{Ma}$ \\
\hline \multicolumn{3}{|c|}{\begin{tabular}{|l|l} 
SOLANACEAE & \\
\end{tabular}} \\
\hline Solanum capsicoides All. & $\begin{array}{l}\text { Melancia-da- } \\
\text { praia }\end{array}$ & $\mathrm{Ca}, \mathrm{Ma}$ \\
\hline Solanum stipulaceum Willd. ex Roem. \& Schult. & Sacatinga & $\mathrm{Ca}, \mathrm{Ce}, \mathrm{Ma}$ \\
\hline
\end{tabular}

Conforme as informações da Tabela 1, em relação à repartição nos domínios fitogeográficos, constata-se que na família Anacardiaceae, as espécies Anacardium occidentale L. e Tapirira guianensis Aubl. apresentam ampla distribuição no território nacional com ocorrência na Amazônia, Caatinga, Cerrado, 
Mata Atlântica, Pampa e Pantanal. No entanto, há espécies que possuem distribuição restrita, Ziziphus joazeiro Mart. e Ficus cyclophylla (Miq.) Miq.. Ambas aparecem em apenas um único domínio fitogeográfico no Brasil, a primeira espécie ocorre na Caatinga e a última, na Mata Atlântica - Floresta Ombrófila aberta e Restinga (STEHMANN et al., 2009).

A espécie E. Guineenses Jacq., o dendê, embora ocorra na área de estudo, não é nativa do Brasil. Ela é uma espécie exótica, originária na Costa ocidental da África, desde as florestas tropicais da costa da Libéria até Angola (LEÃO et al., 2011). Provavelmente, ela foi introduzida no Brasil durante o período colonial, tendo sido trazida pelos africanos, a principal mão de obra da monocultura canavieira desenvolvida na área do domínio da Mata Atlântica. Em terras brasileiras, o dendê (E. guineenses Jacq.) se adaptou aos ambientes de clima quente e úmido, onde os solos são profundos e apresentam diferentes propriedades químicas e físicas (FERNANDES, 2009).

Considerando esse contexto, na atualidade verifica-se a distribuição fitogeográfica da espécie $E$. Guineenses Jacq. no território nacional, associada ao conjunto de formações florestais da Mata Atlântica com diferentes graus de antropização, em particular a Floresta Ombrófila, e ao ecossistema Restinga da região Nordeste, principalmente nos estados da Bahia, Pernambuco e Rio Grande do Norte, e no Sudeste, apenas no Espírito Santo (LEITMAN, et al., 2017). Em Sergipe foram registradas duas coletas, uma em área de Mata Atlântica, no município de Indiaroba e outra, recentemente em ambiente de Restinga, em Brejo Grande, no povoado Santa Cruz, conforme dados disponíveis na rede speciesLink do Centro de Referência em Informação Ambiental (CRIA, 2017).

De acordo com Lorenzi (2008), a espécie A.occidentale L. se desenvolve naturalmente em solos arenosos, campos e dunas da costa norte do país, enquanto a T. Guianensis Aubl. ocorre em todo o território brasileiro, desenvolvendo-se em solos úmidos e distribuindo-se amplamente em ambientes secos e de encosta. Quanto ao Z. Joazeiro Mart., esse mesmo autor afirma que sua predominância é notória no bioma da Caatinga e nos campos abertos, que ocorrem no polígono da seca. Contudo, essa espécie também foi coletada na área de Restinga em que residem as famílias da comunidade Santa Cruz, em razão das características climáticas e edáficas. Da mesma forma, a Syagrus coronata (Mart.) Becc. identificada como pertencente apenas aos domínios da Caatinga e do Cerrado, ocorre na área deste estudo.

Outras espécies além das supracitadas, também apresentaram ampla distribuição, são elas: Senna occidentalis (L.) Link, Hymenaea courbaril L., Centrosema brasilianum (L.) Benth., pertencentes à família Fabaceae. Tal fato, sugere que a ocorrência deve-se às características adaptativas dessa família, que consegue fixar o nitrogênio, se instalar e sobreviver em solos de baixa fertilidade química (RAVEN; EVERT; EICHHORN, 1996). Além disso, estas espécies apresentam diferentes formas e consistências dos 
frutos, que evolutivamente favoreceram a ação de agentes dispersores (NOGUCHI; NUNES; SARTORI, 2009).

$\mathrm{Na}$ Restinga da área de estudo foram registradas espécies que são encontradas com frequência nos domínios da Mata Atlântica e da Amazônia, com base na Flora do Brasil (2017) - A. Occidentale L., T. Guianensis Aubl., Mandevilla hirsuta (A. Rich.) K. Schum., Philodendron acutatum Schott, Lundia corymbifera (Vahl) Sandwith, Protium heptaphyllum (Aubl.) Marchand, Cereus fernambucensis Lem., Chamaecrista hispidula (Vahl) H. S. Irwin \& Barneby, S. occidentalis (L.) Link, Inga capitata Desv., $H$. courbaril L., C. brasilianum (L.) Benth., Myrciaria floribunda (H. West ex Willd.) O.Berg e Tocoyena formosa (Cham. \& Schltdl.) K. Schum.. Essas ocorrências podem ser justificadas pelo estudo desenvolvido por Leitão Filho (1987), que reconhece o possível contato entre diferentes ecossistemas no decorrer do tempo geológico.

As análises efetuadas em relação à ameaça de extinção indicaram que apenas a espécie $F$. Cyclophylla (Miq.) Miq., da família Moraceae, tem sido classificada no status de "em perigo", com base na plataforma IUCN (2017). Essa espécie pertencente à Mata Atlântica é encontrada na Floresta Ombrófila de 12 estados brasileiros, do Nordeste e Sudeste (ROMANIUC-NETO et al., 2017). Contudo, os dados da rede speciesLink indicam que ela foi também coletada em áreas de Restinga e dunas de Pirambu, Santo Amaro das Brotas, Barra dos Coqueiros e Brejo Grande, municípios do litoral norte de Sergipe.

A ocorrência de uma espécie ameaçada reforça a necessidade de se conservar as Restingas de Brejo Grande, uma vez que as comunidades tradicionais, como a do povoado Santa Cruz, dependem dos recursos florísticos para a sua sobrevivência e manutenção da qualidade de vida. É preciso, portanto, aprofundar os estudos referentes às espécies na área como forma de subsidiar projetos de conservação da flora no estado de Sergipe.

\section{Considerações finais}

Os procedimentos metodológicos e as bases teóricas adotadas permitiram conhecer o estado de ameaça e verificar a distribuição das espécies coletadas na Restinga do povoado Santa Cruz, Brejo Grande, nos domínios fitogeográficos brasileiros.

Embora a maior parte dos vegetais consigam se instalar e se desenvolver em mais de um domínio fitogeográfico, foi verificado que determinadas espécies não se enquadram nesse contexto, a exemplo de Ziziphus joazeiro Mart. e Ficus cyclophylla (Miq.) Miq., cuja ocorrência fica restrita a um domínio. As 
análises também revelaram que a $F$. Cyclophylla (Miq.) Miq. se encontra em situação de ameaça, na categoria "em perigo".

Diante dessa situação, recomenda-se que os estudos sobre a flora da Restinga no território sergipano sejam ampliados, a fim de que estes recursos possam ser conservados para as gerações futuras, garantindo ainda a manutenção da biodiversidade.

\section{Bibliografia}

ALVES, N. M. S. Análise geoambiental e socioeconômica dos municípios costeiros do litoral norte do estado de Sergipe - Diagnóstico como subsídio ao ordenamento e gestão do território. Tese (Doutorado em Geografia) Núcleo de Pós-Graduação em Geografia, Pró-Reitoria de Pós-Graduação e Pesquisa, Universidade Federal de Sergipe, 2010.

APG IV. An update of the Angiosperm Phylogeny Group classification for the orders and families of flowering plants: APG VI. Botanical Journal of the Linnean Society, 2016.

BERTRAND, G. Paisagem e geografia física global: esboço metodológico. Caderno de Ciências da Terra, São Paulo, n. 13, p. 1-27, 1972.

BRASIL. Ministério das Minas e Energia. Projeto RADAMBRASIL: folha SC.24/25 Aracaju/Recife: geologia, geomorfologia, pedologia, vegetação, uso potencial da terra. Rio de Janeiro, 1983. 851 p. (Levantamento de Recursos Naturais, 30).

CRIA - CENTRO DE REFERÊNCIA EM INFORMAÇÃO AMBIENTAL. Species link. Disponível em: <http://www.splink.cria.org.br> Acesso em: 15 mar. 2017

DRUMMOND, G. M. et al. Biota Minas: Diagnostico do conhecimento sobre a biodiversidade no Estado de Minas Gerais-subsidio ao Programa Biota Minas. In: Biota Minas: Diagnostico do conhecimento sobre a biodiversidade no Estado de Minas Gerais-subsidio ao Programa Biota Minas. Fundação Biodiversitas, 2009.

FERNANDES, I. O. L. Avaliação energética e ambiental da produção de óleo de dendê para biodiesel na região do baixo sul, Bahia. 2009 151f.. Dissertação (Mestrado em Desenvolvimento Regional e Meio Ambiente) Programa Regional de Pós-Graduação em Desenvolvimento Regional e Meio Ambiente (PRODEMA). Ilhéus: UESC, 2009.

FUNDAÇÃO BIODIVERSITAS. Lista da flora brasileira ameaçada de extinção, segundo avaliação no workshop da fundação biodiversitas. Disponível em: <http://www.biodiversitas.org.br/florabr/lista_florabr.pdf > Acesso em: 14 mar. 2017

GILLUNG, J. P. Biogeografia: a história da vida na Terra. Revista da Biologia, v. esp. 2011.

GIULIETTI, A.M. et al. Biodiversidade e conservação das plantas no Brasil. Megadiversidade, v. 1, n. 1, p. 52-61. 2005.

IBGE - INSTITUTO BRASILEIRO DE GEOGRAFIA E ESTATÍSTICA. Cidades. Sergipe: Brejo Grande. 2017. Disponível em:

http://cidades.ibge.gov.br/xtras/temas.php?lang=\&codmun=280070\&idtema=16\&search=sergipe|brejogrande|sintese-das-informacoes >; Acesso em: 13 mar. 2017

KETTUNEN, M.; TEN BRINK, P. Value of Biodiversity, Documenting EU examples where biodiversity loss has led to the loss of ecosystem services. Brussels, Belgium: The Institute for European Environmental Policy (IEEP), p. 131, 2006. 


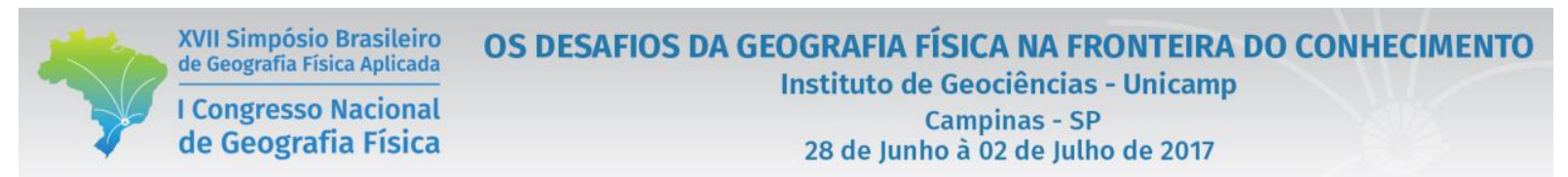

LEÃO, T. C. C et al. Espécies exóticas invasoras no Nordeste do Brasil: contextualização, manejo e políticas públicas. Centro de Pesquisas Ambientais do Nordeste e Instituto Hórus de Desenvolvimento e Conservação Ambiental. Recife, PE, p. 56, 2011.

LEITÃO FILHO, H. F. Considerações sobre a Florística de Florestas Tropicais e sub-tropicais do Brasil. Revista do IPPEF v. 35, p. 41-46, 1987.

LEITMAN, P. et al. Arecaceae in Lista de Espécies da Flora do Brasil. Jardim Botânico do Rio de Janeiro, 2015. Disponível em: <http://floradobrasil.jbrj.gov.br/jabot/floradobrasil/FB22138>.

LISTA DE ESPÉCIES DA FLORA DO BRASIL. Jardim Botânico do Rio de Janeiro. 2017. Disponível em: <http://floradobrasil.jbrj.gov.br/ >. Acesso em: 14 Mar. 2017

LORENZI, H. Árvores brasileiras: manual de identificação e cultivo de plantas arbóreas do Brasil. vol. 1, 5ª ed., Nova Odessa, São Paulo: Instituto plantarum, 2008.

MMA - MINISTÉRIO DO MEIO AMBIENTE. Lista oficial de espécies da flora brasileira ameaçada de extinção, Brasil. Instrução normativa $\mathrm{n}^{\mathrm{o}} 6$ de 23 de setembro de 2008. Disponível em: <http://www.mma.gov.br/estruturas/ascom_boletins/_arquivos/83_19092008034949.pdf> Acesso em: 14 mar. 2017

MORI, S. A.; BOOM, B. M. Southern Bahian moist forests. The Botanical Review, New York, v. 49, n 2, p. 155$232,1983$.

NASCIMENTO, A. R. T.; LONGHI, S. J.; BRENA, D. A. Estrutura e padrões de distribuição espacial de espécies arbóreas em uma amostra de Floresta Ombrófila Mista em Nova Prata, RS. Ciência Florestal, v. 11, n. 1, p. 105$119,2001$.

NOGUCHI, D. K.; NUNES, G. P.; SARTORI, Â. L. B. Florística e síndromes de dispersão de espécies arbóreas em remanescentes de Chaco de Porto Murtinho, Mato Grosso do Sul, Brasil. Rodriguésia, p. 353-365, 2009.

PASSOS, M. M. Biogeografia e paisagem. 2 ed. Maringá:[s.n], 2003.

RAVEN, P. H.; EICHHORN, S. E.; EVERT, R. F.; Biologia vegetal. $5^{\text {a }}$ ed. Rio de Janeiro: Guanabara Koogan, 1996.

ROMANIUC NETO, S. et al. Moraceae in Lista de Espécies da Flora do Brasil. Jardim Botânico do Rio de Janeiro. 2015. Disponível em: <http://floradobrasil.jbrj.gov.br/jabot/floradobrasil/FB10158>. Acesso em: 14 Mar. 2017.

STEHMANN, J.R. et al. Gimnospermas e Angiospermas. Plantas da Floreta Atlântica. Jardim Botânico do Rio de Janeiro, Rio de Janeiro, p.27- 37, 2009.

THE IUCN RED LIST OF THREATENED SPECIES. Version 2013.2. Disponível em: <www.iucnredlist.org> Acesso em: 14 mar. 2017 